\title{
Spare half, share the rest: A revised planetary boundary for biodiversity intactness and integrity
}

Fabrice DeClerck ( $\nabla$ f.declerck@cgiar.org )

Bioversity International

\section{Sarah Jones}

Alliance of Bioversity and CIAT, One CGIAR

Natalia Estrada-Carmona

Bioversity International

Alexander Fremier

Washington State University

\section{Biological Sciences - Article}

Keywords: biodiversity, planetary boundary, ecology

Posted Date: April 15th, 2021

DOl: https://doi.org/10.21203/rs.3.rs-355772/v1

License: (c) (i) This work is licensed under a Creative Commons Attribution 4.0 International License. Read Full License 
1 Title

2 Spare half, share the rest: A revised planetary boundary for biodiversity intactness and integrity

\section{Summary paragraph}

4 Setting clear biodiversity targets is a pervasive challenge ${ }^{1}$ due to the context-dependent nature

5 of biodiversity that has evaded concise science-based objectives akin to the climate change

6 target of limiting global warming to $1.5^{\circ} \mathrm{C}^{2}$. Considering the major risk to biodiversity and

7 human wellbeing of continued inaction, it is imperative to identify similarly operational and

8 science-based boundaries supporting the development of targets to safeguard biodiversity and

9 its contributions to human well-being. Confounding goal setting are the two distinct but not

10 mutually exclusive conservation objectives: (1) halting the rampant loss of intact ecosystems,

11 species extinction and population declines, and (2) maintaining biosphere integrity and

12 ecosystem function. We propose a revised planetary boundary for biodiversity: retaining at

13 least half of the area of each terrestrial ecoregion biologically intact to halt the extinction crisis

14 and maintaining ecosystem integrity across all lands to preserve and regenerate biosphere,

15 ecosystem functions and their contributions to human well-being. We combine four proxy

16 datasets for biologically intact habitat to identify areas consistently identified as intact and find

17 that $49.6 \%$ of the Earth's ice-free land remains intact. While this is promising globally, $69 \%$ of

18798 unique ecoregions are less than half intact. For ecosystem integrity, we find $18.1 \%$ of

19 working lands have severe ecosystem integrity deficits precluding the provisioning of biosphere

20 and ecosystem functions. Ninety percent of unique ecoregions have an ecosystem integrity

21 deficit. Globally, intactness and integrity are at or have surpassed boundary limits with

22 degradation of nature critically jeopardizing biosphere capacity to support a safe and just space 
23 for humanity. Combined efforts are needed to avoid further loss of and restore intactness,

24 while regenerating integrity in working lands. 


\section{Main text}

\section{Introduction}

Biodiversity is in crisis facing catastrophic conversion and losses of ecosystems and the

28 unique species and genetic diversity they harbour ${ }^{3-6}$. This loss increasingly has regional and

29 global scale impacts on earth systems processes spanning from carbon and water cycles, to

30 pollination and pest and disease regulation? ${ }^{7}$. The absence of meaningful system-wide indicators

31 hinders global policy by failing to provide politically relevant status measures and targets to

32 align and galvanize conservation action ${ }^{1}$. Without clear, science-based but politically actionable

33 guardrails, we risk losing a pivotal decade of progress in bending the curve on biodiversity loss ${ }^{8}$.

34 The biodiversity research community has thus far largely resisted setting concise

35 scientific targets due to well-founded concerns that species, and associated ecosystem services,

36 are inherently local and that ecology is more complex and more localized than climate, and thus

37 not amenable to system-wide targets ${ }^{9}$. However, considering the acute nature of the on-going

38 biodiversity crisis $^{6}$, setting evidence-based science targets can be an effective means to foster

39 alignment, identify effective actions, and set up processes to track progress across stakeholder

40 groups $^{10}$. As demonstrated by the Paris Climate Convention, and by the EAT-Lancet

41 Commission ${ }^{11}$, global targets can be set that are compatible with local conservation priority

42 setting and that recognize the diversity of context specific conservation actions. More critically,

43 agreed upon targets and system-wide boundary metrics can provide standardized scientific

44 assessments of biodiversity and ecosystem function status and trends that align local action

45 against global goals. 
We propose biodiversity intactness and ecosystem integrity as two complementary

47 planetary boundary measures of biodiversity (Box 1). Biodiversity intactness and ecosystem

48 integrity are analogous to the first two goals (Goal A and Goal B) proposed by the Convention

49 on Biological Diversity $(\mathrm{CBD})^{12}$. Both biodiversity intactness and ecosystem integrity are

50 evaluated here from spatially gridded datasets. These data can be aggregated over any larger

51 region, such as regions defined by administrative (e.g., country, continent) or ecological (e.g.,

52 ecosystem, ecoregion, biome, global) boundaries, or a combination of these (e.g., ecoregions

53 within countries) to facilitate setting ecologically meaningful and politically actionable targets.

54 We provide a global assessment of intactness and integrity to facilitate countries setting

55 ambitious goals for protection, restoration, and regeneration.

57 Biodiversity Intactness

The conceptual definition of biodiversity intactness describes the state of an ecosystem

59 being unimpaired from post-industrial human alteration (Box 1$)^{13}$. Biodiversity intactness is a

60 measure of biodiversity status measured as the relative abundance of originally present species

61 or level of human pressures ${ }^{13,14}$. Intact areas, by definition have integrity and maintain

62 ecological functions, for example climate mitigation and regulation ${ }^{14}$. Retaining intact nature

63 globally is required to halt the loss of wild biodiversity, and both the earth system, and

64 ecosystem services it provides. While nuances of conservation efforts are important, including

65 fragmentation, habitat size and extent, maintaining at least half of the global land mass as

66 intact has been proposed as required to avert massive species loss ${ }^{15-18}$. Half intact improves on

67 previous articulations of the Biosphere Integrity planetary boundary by adding an area-based 
68 complement to intactness, making it easily operational. Half intact is synonymous with the "no

69 net loss or net gain" targets proposed by the CBD under Goal A. We apply the concept of half

70 intact at the ecoregion level to assess the conservation of the unique local biological

71 composition across the globe that require protection. Intactness levels below this boundary

72 increase irreversible extinction risks, a threshold which has been passed in $69 \%$ of

73 ecoregions ${ }^{1,15,18}$. Remaining above the intactness boundary requires important sparing of

74 terrestrial and aquatic ecosystems from conversion ${ }^{19,20}$.

75 Ecosystem Integrity

76 Integrity is conceptually defined as an ecosystem's functional capacity to contribute to

77 biosphere processes and to produce ecosystem services (Box 1$)^{21}$. These include both Earth

78 system-scale processes regulated by the biosphere as well as finer scale ecosystem services

79 provided at the basin, landscape, farm, field, or even neighbourhood scale in urban settings ${ }^{7,22-}$

$80 \quad 25$. Non-intact area can have integrity if they retain sufficient functional biodiversity to support

81 ecosystem service provision ${ }^{26-29}$ irrespective of whether the species or communities they

82 contain are native or not ${ }^{30}$.

83 The spatial extent of the services provided by species often operates at the sub-

84 kilometer scale ${ }^{25,31-40}$. While there is significant context specificity in how biodiversity provides

85 ecosystem services ${ }^{41,42}$, the decay of ecosystem services with increasing distance from

86 provisioning habitat is consistently demonstrated in agroecological and ecosystem service

87 studies. For example, the number and abundance of species able to provide pollination or pest

88 control services, rapidly decreases with the decrease in the area of habitat available $\mathrm{e}^{33,43-49}$ and

89 with increasing distance from source habitat ${ }^{32-34,37-39,47-57}$. Particularly in agricultural landscapes, 
ecosystem service provisioning is related to the farm or field scale such as nutrient delivery (e.g.

91 nitrogen fixation (0.1-1 m), reduction of soil and sediment loss (1-10 m), pollination (10-1000

$92 \mathrm{~m})$, pest control $(10-1000 \mathrm{~m}))^{25}$. Thus, while specific services provided by distinct ecological

93 communities will remain deeply contextual ${ }^{41,42}$, and the subject of both interesting and

94 important research, evidence suggests that natural habitat extent and proximity is a coarse

95 indicator of potential ecosystem service provisioning. More specifically, the absence of semi-

96 natural or natural habitat within a few hundred meters of any given area indicates insufficient

97 associated biodiversity to provide ecosystem services to that area, particularly services that

98 support food production ${ }^{58}$.

99 We use the proportion of natural or semi-natural habitat within a landscape as our

100 operational definition of ecosystem integrity (Box 1; see methods for definitions of natural and

101 semi-natural) and propose an integrity boundary of at least $10 \%$ natural or semi-natural habitat

102 per square kilometre. This integrity boundary represents the minimum surrounding natural or

103 semi-natural habitat needed to maintain the functional biodiversity providing ecosystem

104 services (see methods). Others have proposed a more conservative $20 \%$ boundary for

105 maintaining integrity ${ }^{44}$. We compute integrity levels using $10 \%, 20 \%$ and $30 \%$ to estimate

106 sensitivity of threshold selection.

107

Intactness and integrity capture two distinct but complementary conservation priorities:

108 halting extinction loss and maintaining ecosystem and biosphere function. Achieving intactness

109 targets and halting the loss of biodiversity requires reducing and eliminating pressures such as

110 habitat loss and conversion. Restoring intactness is difficult and in the case of species

111 extinction, nearly impossible to fully recover ${ }^{59}$. Integrity, in contrast, is more readily repairable 
112 and can be provided by biodiverse ecosystems with low intactness scores but functional

113 composition approaching that of intact ecosystems (e.g., non-native species or novel

114 ecosystems $)^{26-28}$. This is the premise of nature-based solutions offered by agroecology,

115 regenerative agriculture, or integrated landscape management initiatives ${ }^{45,46,60-62}$. Integrity

116 targets are achieved by combined actions sparing currently intact ecosystems from conversion,

117 but also requires sharing space for biodiversity in working lands ${ }^{20,45,46}$.

Box 1: Defining biodiversity intactness and ecosystem integrity and related thresholds

\begin{tabular}{|c|c|c|}
\hline & Biodiversity Intactness & Ecosystem Integrity \\
\hline $\begin{array}{l}\text { Conceptual } \\
\text { Definition }\end{array}$ & $\begin{array}{l}\text { The state of an ecosystem's } \\
\text { species composition and } \\
\text { abundance being } \\
\text { unimpaired from post-industrial } \\
\text { human alteration }\end{array}$ & $\begin{array}{l}\text { The state of an ecosystem's } \\
\text { capacity to provide contributions } \\
\text { to Earth system and ecosystem } \\
\text { processes }\end{array}$ \\
\hline $\begin{array}{l}\text { Operational } \\
\text { Definitions }\end{array}$ & $\begin{array}{l}\text { Agreement across globally } \\
\text { consistent layers of intactness } \\
\text { as measured using degree of } \\
\text { human modification and/or } \\
\text { species composition (see } \\
\text { Methods) }\end{array}$ & $\begin{array}{l}\text { Percent of proximate natural or } \\
\text { semi-natural habitat (see } \\
\text { Methods) }\end{array}$ \\
\hline $\begin{array}{r}\text { Boundary } \\
\text { (evidence-based) }\end{array}$ & $\begin{array}{l}\text { All ecoregions having }>50 \% \\
\text { lands designated intact }\end{array}$ & $\begin{array}{l}\text { An area has }>10 \% \text { proximate } \\
\text { natural or -semi-natural } \\
\text { habitat (see Methods) }\end{array}$ \\
\hline Target & Same as Boundary & $\begin{array}{l}100 \% \text { of lands within an ecoregion } \\
\text { have }>10 \% \text { surrounding semi - } \\
\text { natural or natural lands (see } \\
\text { Methods) }\end{array}$ \\
\hline
\end{tabular}

\section{Global Status of Biodiversity Intactness}

We applied an ensemble approach to map intactness by selecting four available

121 datasets of human influence on the global land surface. We applied a threshold to each of the 
122 datasets to identify areas with the lowest human impact and highest portion of biologically

123 intact land remaining (Supplemental Fig. 1; Supplemental data table 1). We combined the four

124 datasets

125

Figure 1: (a) Cell-by-cell measures of intactness (ensemble model Et3) and integrity (10\%

embedded natural lands; (b) Percent intact land by ecoregion; (c) Percent land above the 10\% integrity target by ecoregion.

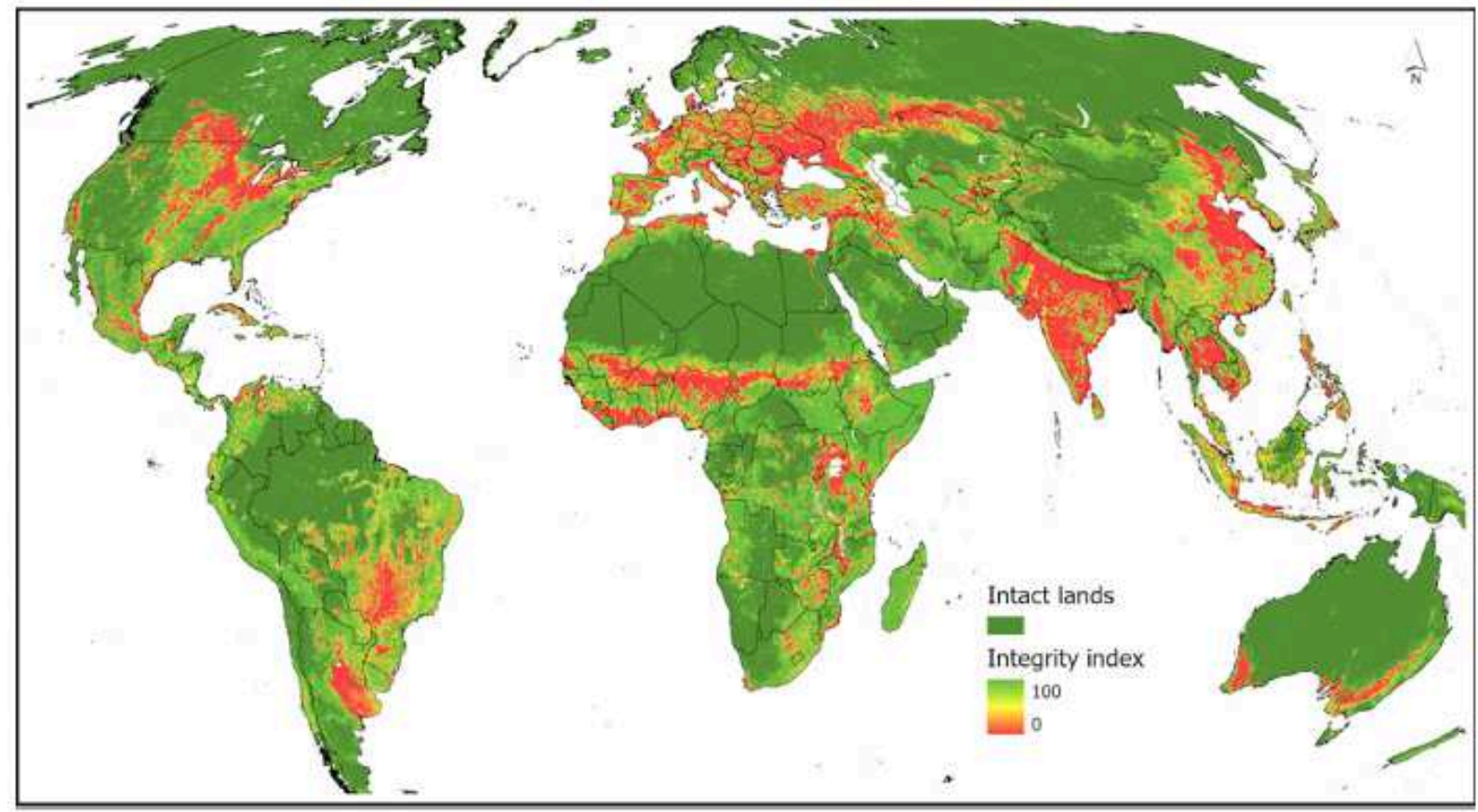

a.
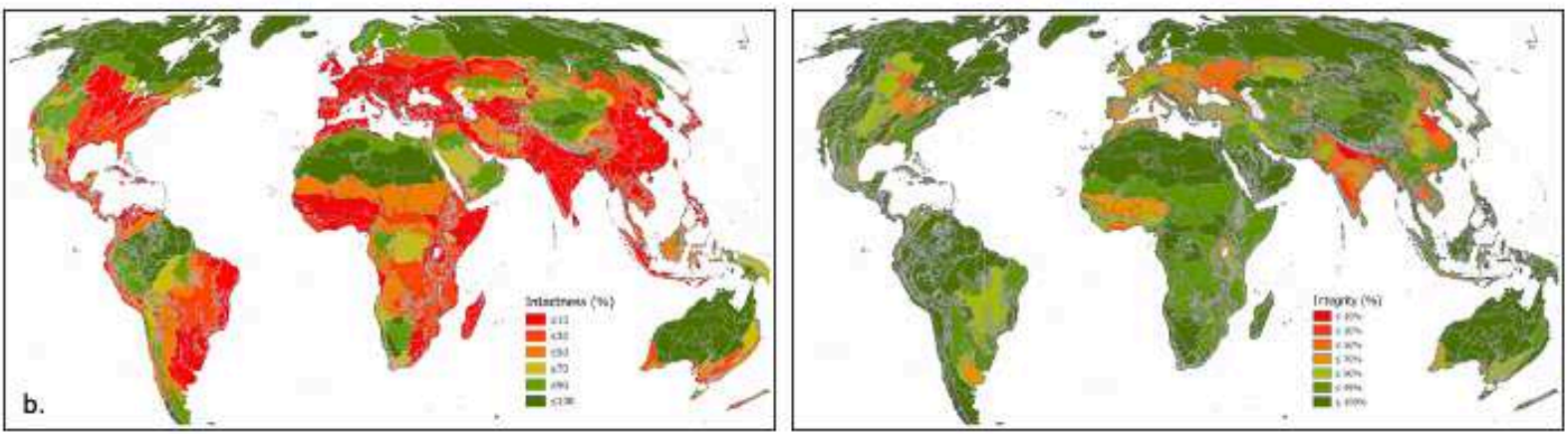
128 into one ensemble dataset of intactness, by classifying a pixel as intact only when three of the 129 four input datasets agreed (Fig. 1a). The ensemble approach provides a robust description of 130 the extent of biological intactness globally. We found $49.6 \%$ of the global ice-free land is intact.

131 However, these intact lands are inequitably distributed across ecoregions. For example, 552 of

132798 ecoregions (69\%) have less than 50\% intact land; and 206 ecoregions have less than $10 \%$

133 intact (Fig 1b Supplemental table 4; $36 \%$ of ecoregions or $27 \%$ of land surface). Non-arable

134 lands make up $38 \%$ of the terrestrial land surface and are dominant areas of intactness: Tundra

135 (100\% intact), Boreal Forests/Taiga (99\% intact) and Deserts and Xeric Shrublands (77\% intact)

136 (Supplemental table 3; data at https://rpubs.com/afremier/SuppTable Biomes data 2021).

137 Ensuring that all ecoregions are above the biodiversity intactness boundary level would entail

138 restoring 23.9 million $\mathrm{km}^{2}$, or $18.1 \%$ of the global land surface, notably in the Tropical and

139 Subtropical Dry Broadleaf Forests and Mangroves biomes (Supplemental Table 3). While

140 restoration can increase intactness in these locations, recovery to preindustrial levels is unlikely

141 (data at https://rpubs.com/afremier/SuppTable ER data 2021).

143 Global Status of Ecosystem Integrity

144 While important global analysis of ecosystem services have been conducted ${ }^{63}$, global

145 analyses of ecosystem integrity remain in their infancy and have not been conducted at the

146 ecoregion scale ${ }^{64,65}$. We used globally available, temporally repeated, and stable land cover

147 mapping dataset created by the European Space Agency Climate Change Initiative (ESACCI-LC)

148 to assess ecosystem integrity. We define lands as having integrity if they have at least $10 \%$ 
149 natural or semi-natural habitat within 1 square $\mathrm{km}$. We propose that the boundary condition

150 needs to be met in all lands because retaining ecosystem integrity underpins the provision and

151 resilience of ecosystem services required for human well-being including for example, food,

152 nutition $^{66}$, climate ${ }^{62}$, and water security ${ }^{1,67}$ (see methods: Establishing Ecosystem Integrity).

153 Globally, $18.2 \%$ of all lands, and $23 \%$ of the human-dominated lands are below the

154 integrity boundary, an equivalent of $120.0 \mathrm{M} \mathrm{km}^{2}$ (Supplemental Table 5). In these areas

155 insufficient ecosystem integrity exists to maintain ecosystem service provision such as

156 pollination of crops, or regulation of agricultural pests and diseases ${ }^{43,68}$. Increasing the integrity

157 boundary to $20-30 \%$ per $\mathrm{km}^{2}$ in human dominated lands has been proposed to the $\mathrm{CBD}^{10}$. We

158 estimate that $32.8 \%$ and $40.3 \%$ of human dominated lands fail to meet the $20 \%$ and $30 \%$

159 integrity boundary respectively (Supplemental Table 5). We find that 741 of 821 ecoregions

160 (90.3\%) have integrity deficits on at least some lands (with a 10\% boundary). Ecoregions with

161 the largest integrity deficits are concentrated in some of the world's most populous and

162 agriculturally productive regions, namely India's Punjab, the Midwestern states of the United

163 States, north-eastern China, eastern Europe, west Africa, and California's central valley (Fig. 1c,

164 https://rpubs.com/afremier/SuppTable_ER data_2021). Ecosystem integrity as defined and

165 measured here provides a scalable and repeatable approach for monitoring the nature

166 contributions to people.

167

168 Global patterns of ecoregion intactness and integrity 
170 conservation measures reconciles the land-sharing versus land sparing debate ${ }^{19,20,45}$; which

171 while ecologically interesting, has become a dangerous distraction interpreted as an either/or

Figure 2: Intactness and Integrity values for each ecoregion plotted by biome; point size is relative to the size of the ecoregion in question. Colored bins show ecoregions with show intersection of regions with low $(<40 \%)$, medium (40-60\%), medium-high (60-80\%), and high (>80\%) intactness; and low (<50\%), medium (50-80\%), and high (>80\%) integrity.
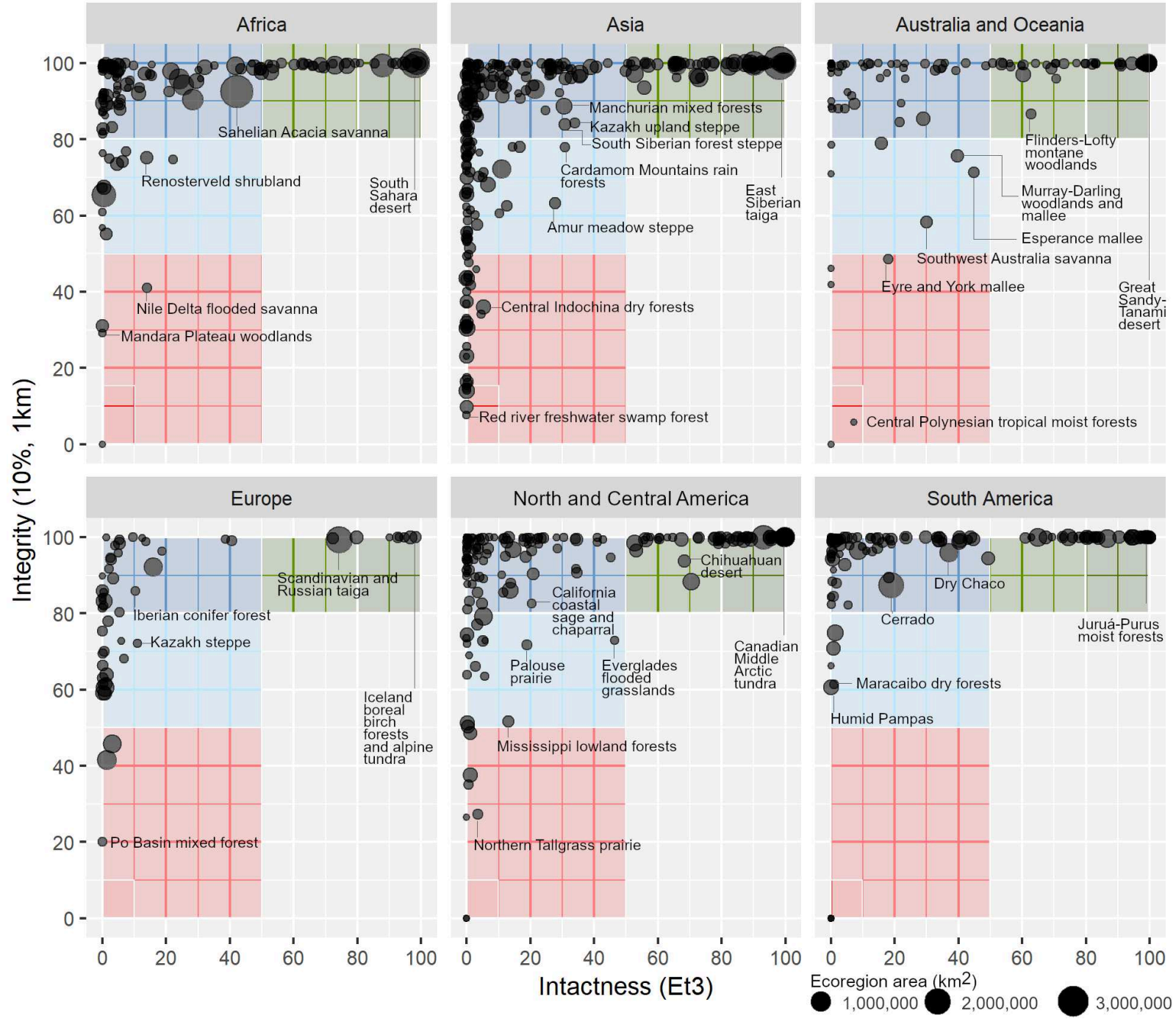
173 scenario ${ }^{28}$. In order to secure intactness and integrity, sparing currently intact lands from

174 conversion, restoring ecoregion area to at least half intact, and sharing the rest by embedding

175 natural habitat into human dominated lands to maintain integrity becomes a concise

Figure 3: Mapped Intactness and Integrity values for each ecoregion; Colored bins are taken from figure 2 .

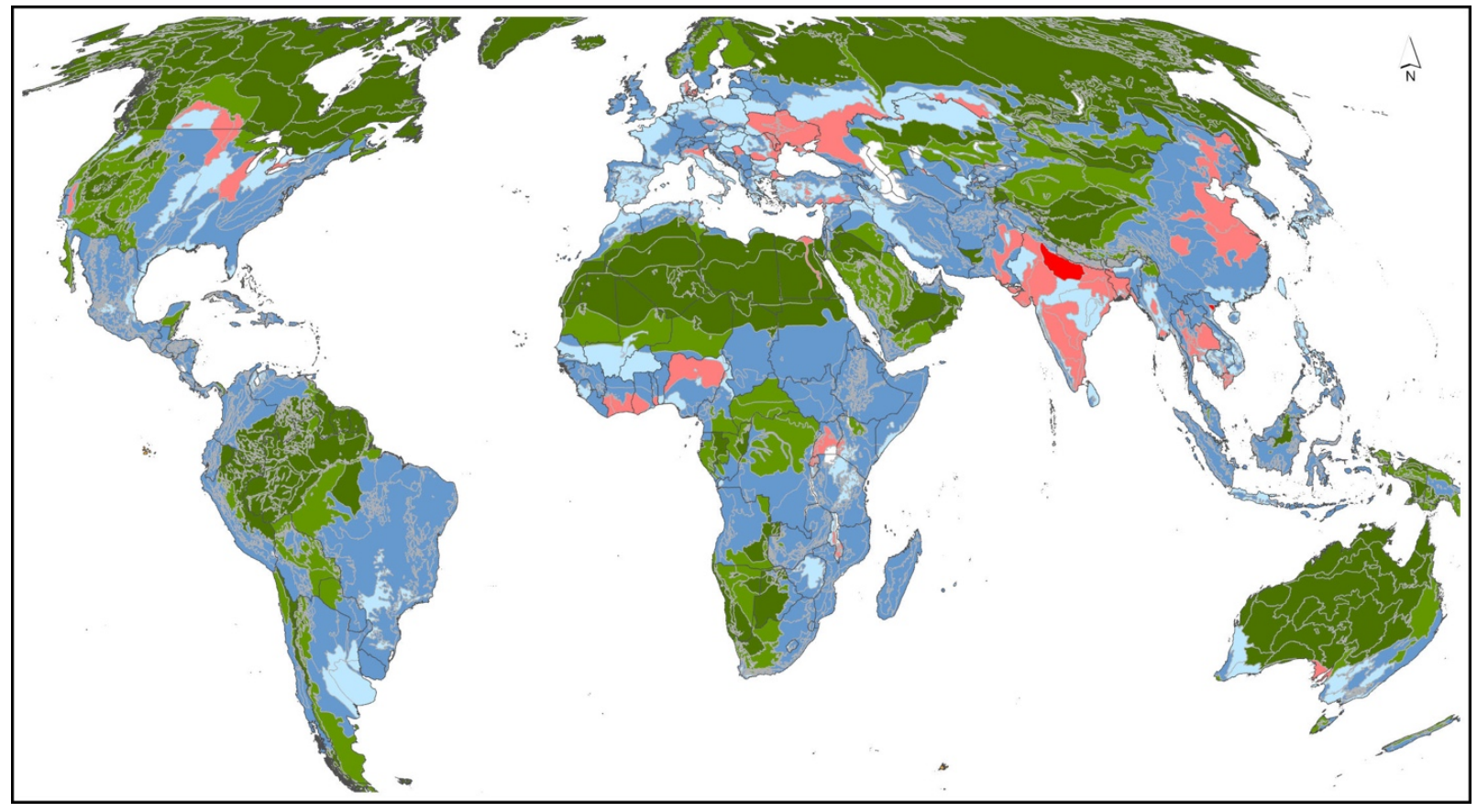

176 conservation objective compatible with the post-2020 Aichi Goals A and B and a quantifiable

177 application of no net loss targets. Plotting the intactness and integrity of ecoregions around the

178 world creates an integrated characterization of biodiversity and ecosystem status (Figs. 2-3)

179 serving as a baseline for the 2020 condition for CBD Goals (i.e., A and B) ${ }^{12}$. The joining of

180 national boundaries and ecoregion boundaries created 1745 unique country-ecoregions for

181 which we can provide intactness and integrity status measures (Fig. 3) against which nationally

182 determined contributions towards evidence-based targets for nature can be assessed and set,

183 e.g., to align with the recent proposal emerging from the broad multi-actor dialogues defining a 
184 global goal for nature as "no net-loss of nature from 2020, net-positive by 2030 and full 185 recovery by $2050 "$.

186 Our analysis identifies three generalized categories of country-ecoregion status of 187 combined intactness and integrity measures: (1) high integrity, high intactness (Fig. 3 dark 188 green regions (29\% surface land)), (2) high integrity, low intactness (Fig. 2 \& Fig. 3 blue regions 189 (54\%)) and (3) low integrity and intactness (Fig. 2 \& Fig. 3 pink and red regions (17\%)). Regions 190 of high integrity, but low intactness (blue) encompass $54 \%$ of the land surface or $71.3 \mathrm{M} \mathrm{km}^{2}$. In 191 these country ecoregions intactness has been lost, with high extinction risk or major extinctions 192 having already occurred; yet, they have retained minimum required biodiversity to secure 193 ecosystem services. At the other extreme are country ecoregions which have both low 194 intactness and low integrity. These are regions of significant conservation concern where 195 species conservation objectives are imperilled, quite possibly beyond the point of no return, 196 and where insufficient ecosystem integrity remains to ensure the provisioning of ecosystem 197 services (Fig. 3; pink and red regions). One hundred and thirty-six country ecoregions (17\%) 198 covering $21.05 \mathrm{M} \mathrm{km}^{2}$ are in this category and at risk of functional collapse.

200 Avoid loss, Restore Intactness, Regenerate Integrity

201 The functional role that biodiversity plays in a safe, just, and stable earth system

202 requires a whole Earth approach that that maintains integrity across the entire terrestrial

203 landmass. For biosphere level processes, large tracks of intact ecosystems are best suited to 204 stabilize climate, regulate hydrological cycles, and avert mass extinction of biodiversity. Climate 205 regulation is particularly sensitive to the quality and extent of intact tropical and boreal forest 
206 ecosystems ${ }^{62,69-71}$. Halting the loss of biodiversity, however, requires setting multi-level targets

207 including at ecoregion level in light of the unique combinations and composition of species they

208 represent ${ }^{15,17}$. Focusing efforts to retain intactness on any single biome or ecoregion is an

209 ecological non-sequitur; the absolute loss of 371 ecoregions with less than 10\% intactness, 206

210 of which have less that $1 \%$ intactness, is one of the most sobering results of our analysis.

211 Safeguarding intactness in the remaining $49.6 \%$ of the global land surface is a necessary

212 precondition to maintain ecosystem functions, nature's contribution to people and earth

213 system resilience. Setting more ambitious targets beyond boundary conditions is critical both to

214 further reduce extinction risk and to ensure more resilient biosphere.

215 Globally there are $65.5 \mathrm{M} \mathrm{km}^{2}$ of intact lands, or $49.6 \%$ of the land surface (Supp Table

216 4). Intact areas in ecoregions require continued conservation commitments to achieve no net

217 loss $^{72}$. Returning to intactness levels above boundary conditions (i.e. $>50 \%$ ) for all ecoregions

218 would require restoring $24 \mathrm{M} \mathrm{km}^{2}$ of land and, with no additional loss of existing intact land,

219 result in intact land covering 69\% of the Earth's terrestrial land. We find that 314 of 1745 (18\%)

220 country ecoregions have $<10 \%$ intact lands which we consider post or near-extinction and

221 possibly non-restorable (Supplemental Table 4, https://rpubs.com/afremier/CER). Retaining

222 and restoring the intact areas in these endangered eco-regions needs urgent and critical

223 attention (Figs 2-3).

224 In light of the critical contributions of biodiversity to human well-being though their role

225 in providing ecosystem services, or nature's contributions to people, the non-intact half of our

226 planet cannot become an ecological sacrifice zone. This half must retain sufficient ecological

227 integrity, through retention of sufficient natural and semi-natural habitat at small and large 
228 scales, to produce food, regulate pests and diseases, provide safe passage to biodiversity, and

229 contribute to gene flow, regulating water cycles, offer spiritual and recreational spaces and

230 mitigating climate change amongst others ${ }^{73}$. We find that $18.6 \%$ of the earth's surface has a

231 critical deficit in ecological integrity where ecosystem services are likely to be at severe risk or

232 are no longer being provided. Regenerating integrity would require efforts on between 12.1-

$23317.5 \mathrm{M} \mathrm{km}^{2}$ of land, largely consisting of the diversification of agricultural lands. Countless

234 context specific options for maintaining or regenerating ecological integrity exist and are

235 compatible with food, nutrition, and livelihood security objectives ${ }^{74}$.

236 Global conservation objectives serve to align national and local conservation actions,

237 and human well-being needs while retaining local decision-making authority. Conservation and

238 restoration actions should match local abilities and priorities starting by targeting key

239 biodiversity areas (KBA's), unique ecological communities, conservation hotspots, and locally

240 intact areas, while recognizing and respecting local and indigenous stewardship. Intactness, as

241 defined here, does not preclude human activities compatible with retaining intactness as found

242 in some forms of rangeland or forest management. Actions for regenerating integrity are

243 similarly diverse and well-documented. The choice whether to set bold targets for intactness

244 and integrity is a socio-political one. Nonetheless, clear, spatially explicit, and biologically

245 meaningful targets of intactness and integrity demonstrate what and where biodiversity has

246 already been lost and serve to help prioritise future policy actions to reduce the risk and

247 consequences of further loss. Our assessment, as that of numerous complementary studies, is

248 that in too many places, the loss of intactness and integrity is too high severely compromising

249 biosphere capacity to provide a safe and just space for humanity ${ }^{75}$. 
250 Our intactness and integrity boundaries provide a globally applicable, science based,

251 foundation for target setting that can be operationalized at multiple actionable levels for

252 prioritizing conservation, restoration, and regeneration efforts. Besides, it facilitates traceability

253 and accountability of global trade driving biodiversity loss. Our assessment provides a spatially

254 explicit baseline and targets of both intactness and integrity against which country

255 commitments and efforts can be assessed while leaving ample opportunity for countries and

256 private sector, and their citizenry to identify and implement effective context specific, locally

257 adapted restoration and regeneration actions. It is our hope that such assessments can be used

258 to guide decisive actions in this UN decade of restoration to begin bending the biodiversity

259 curve for no net loss, or net positive by 2030. 
2611 Maron, M., Simmonds, J. S. \& Watson, J. E. Bold nature retention targets are essential 
DeClerck, F. A. et al. Agricultural ecosystems and their services: the vanguard of sustainability? Current opinion in environmental sustainability 23, 92-99 (2016). Fremier, A. K. et al. Understanding Spatiotemporal Lags in Ecosystem Services to Improve Incentives. Bioscience 63, 472-482, doi:10.1525/bio.2013.63.6.9 (2013).

26 Díaz, S. \& Cabido, M. Vive la différence: plant functional diversity matters to ecosystem processes. Trends in ecology \& evolution 16, 646-655 (2001). Laliberte, E. et al. Land-use intensification reduces functional redundancy and response diversity in plant communities. Ecology letters 13, 76-86 (2010). Flynn, D. F. et al. Loss of functional diversity under land use intensification across multiple taxa. Ecology letters 12, 22-33 (2009).

29 Hooper, D. U. et al. Effects of biodiversity on ecosystem functioning: a consensus of current knowledge. Ecological monographs 75, 3-35 (2005).

30 Evers, C. R. et al. The ecosystem services and biodiversity of novel ecosystems: A literature review. Global ecology and conservation 13, e00362 (2018).

31 Klein, A. M., Steffan-Dewenter, I. \& Tscharntke, T. Pollination of Coffea canephora in relation to local and regional agroforestry management. J Appl Ecol 40, 837-845 (2003).

32 Klein, A. M., Steffan-Dewenter, I. \& Tscharntke, T. Foraging trip duration and density of megachilid bees, eumenid wasps and pompilid wasps in tropical agroforestry systems. $J$ Anim Ecol 73, 517-525 (2004).

33 Kremen, C. et al. Pollination and other ecosystem services produced by mobile organisms: a conceptual framework for the effects of land-use change. Ecology Letters 10, 299-314, doi:10.1111/j.1461-0248.2007.01018.x (2007).

34 Steffan-Dewenter, I., Munzenberg, U., Burger, C., Thies, C. \& Tscharntke, T. Scaledependent effects of landscape context on three pollinator guilds. Ecology 83, 14211432 (2002).

35 Steffan-Dewenter, I. \& Tscharntke, T. Effects of habitat isolation on pollinator communities and seed set. Oecologia 121, $432-440$ (1999).

36 Thies, C., Steffan-Dewenter, I. \& Tscharntke, T. Effects of landscape context on herbivory and parasitism at different spatial scales. Oikos 101, 18-25 (2003).

37 Avelino, J., Romero-Gurdian, A., Cruz-Cuellar, H. F. \& Declerck, F. A. J. Landscape context and scale differentially impact coffee leaf rust, coffee berry borer, and coffee root-knot nematodes. Ecological Applications 22, 584-596 (2012).

38 Martínez-Salinas, A. et al. Bird functional diversity supports pest control services in a Costa Rican coffee farm. Agriculture, Ecosystems \& Environment 235, 277-288 (2016).

39 Ricketts, T. H. Tropical forest fragments enhance pollinator activity in nearby coffee crops. Conservation Biology 18, 1262-1271 (2004).

40 Sirami, C. et al. Increasing crop heterogeneity enhances multitrophic diversity across agricultural regions. Proceedings of the National Academy of Sciences 116, $16442-$ 16447 (2019).

41 Karp, D. S. et al. Crop pests and predators exhibit inconsistent responses to surrounding landscape composition. Proceedings of the National Academy of Sciences 115, E7863E7870 (2018).

42 Tscharntke, T. et al. When natural habitat fails to enhance biological pest control-Five hypotheses. Biological Conservation 204, 449-458 (2016).

43 Chaplin-Kramer, R., O’Rourke, M. E., Blitzer, E. J. \& Kremen, C. A meta-analysis of crop pest and natural enemy response to landscape complexity. Ecology letters 14, 922-932 (2011).

44 Garibaldi, L. A. et al. Working landscapes need at least 20\% native habitat. Conservation Letters, e12773 (2020).

45 Kremen, C. Reframing the land-sparing/land-sharing debate for biodiversity conservation. Annals of the New York Academy of Sciences 1355, 52-76 (2015). 
$36046 \quad$ Kremen, C. \& Merenlender, A. M. Landscapes that work for biodiversity and people.

361

362

363

364

365

366

367

368

369

370

371

372

373

374

375

376

377

378

379

380

381

382

383

384

385

386

387

388

389

390

391

392

393

394

395

396

397

398

399

400

401

402

403

404

405

406

407

408

409

410

Science 362 (2018).

47 Kremen, C., Williams, N. M., Bugg, R. L., Fay, J. P. \& Thorp, R. W. The area requirements of an ecosystem service: crop pollination by native bee communities in California. Ecology letters 7, 1109-1119 (2004).

48 Ricketts, T. H. et al. Landscape effects on crop pollination services: are there general patterns? (vol 11, pg 499, 2008). Ecology Letters 11, 1121-1121, doi:10.1111/j.14610248.2008.01241.x (2008).

49 Tscharntke, T. et al. Landscape moderation of biodiversity patterns and processes eight hypotheses. Biological Reviews 87, 661-685, doi:10.1111/j.1469-

185X.2011.00216.x (2012).

50 Denys, C. \& Tscharntke, T. Plant-insect communities and predator-prey ratios in field margin strips, adjacent crop fields, and fallows. Oecologia 130, 315-324 (2002).

51 Klein, A. M., Steffan-Dewenter, I. \& Tscharntke, T. Fruit set of highland coffee increases with the diversity of pollinating bees. P Roy Soc Lond B Bio 270, 955-961 (2003).

52 Krauss, J., Steffan-Dewenter, I. \& Tscharntke, T. How does landscape context contribute to effects of habitat fragmentation on diversity and population density of butterflies? $J$ Biogeogr 30, 889-900 (2003).

53 Schmidt, M. H., Roschewitz, I., Thies, C. \& Tscharntke, T. Differential effects of landscape and management on diversity and density of ground-dwelling farmland spiders. J Appl Ecol 42, 281-287 (2005).

54 Schmidt, M. H. \& Tscharntke, T. Landscape context of sheetweb spider (Araneae : Linyphiidae) abundance in cereal fields. J Biogeogr 32, 467-473 (2005).

55 Tscharntke, T., Klein, A. M., Kruess, A., Steffan-Dewenter, I. \& Thies, C. Landscape perspectives on agricultural intensification and biodiversity - ecosystem service management. Ecology Letters 8, 857-874, doi:10.1111/j.1461-0248.2005.00782.x (2005).

56 Westphal, C., Steffan-Dewenter, I. \& Tscharntke, T. Mass flowering crops enhance pollinator densities at a landscape scale. Ecology Letters 6, 961-965 (2003).

57 Diekötter, T., Billeter, R. \& Crist, T. O. Effects of landscape connectivity on the spatial distribution of insect diversity in agricultural mosaic landscapes. Basic and Applied Ecology 9, 298-307 (2008).

58 Frei, B. et al. A brighter future: Complementary goals of diversity and multifunctionality to build resilient agricultural landscapes. Global Food Security 26, 100407 (2020).

59 Benayas, J. M. R., Newton, A. C., Diaz, A. \& Bullock, J. M. Enhancement of biodiversity and ecosystem services by ecological restoration: a meta-analysis. science $325,1121-$ 1124 (2009).

60 Carmenta, R. et al. Characterizing and Evaluating Integrated Landscape Initiatives. One Earth 2, 174-187 (2020).

61 Wood, S. L. et al. Distilling the role of ecosystem services in the Sustainable Development Goals. Ecosystem services 29, 70-82 (2018).

62 Griscom, B. W. et al. Natural climate solutions. Proceedings of the National Academy of Sciences 114, 11645-11650 (2017).

63 Chaplin-Kramer, R. et al. Global critical natural assets. bioRxiv (2020).

64 Martin, C. A. \& Proulx, R. Level-2 ecological integrity: Assessing ecosystems in a changing world. Perspectives in Ecology and Conservation 18, 197-202 (2020).

65 Blumetto, O. et al. Ecosystem Integrity Index, an innovative environmental evaluation tool for agricultural production systems. Ecological indicators 101, 725-733 (2019).

66 Chaplin-Kramer, R. et al. Global malnutrition overlaps with pollinator-dependent micronutrient production. Proceedings of the Royal Society B: Biological Sciences 281, 20141799 (2014). 
41167 Jung, M. et al. Areas of global importance for terrestrial biodiversity, carbon, and water.

412 bioRxiv (2020).

41368 Rusch, A. et al. Agricultural landscape simplification reduces natural pest control: A

$414 \quad$ quantitative synthesis. Agriculture, Ecosystems \& Environment 221, 198-204 (2016).

$41569 \quad$ Chapman, M. et al. Large climate mitigation potential from adding trees to agricultural

$416 \quad$ lands. Global change biology 26, 4357-4365 (2020).

$417 \quad 70$ Rockstrom, J. et al. A safe operating space for humanity. Nature 461, 472-475,

418 doi:10.1038/461472a (2009).

41971 Steffen, W. et al. Planetary boundaries: Guiding human development on a changing

$420 \quad$ planet. Science 347 (2015).

$42172 \quad$ Marquardt, S. G. et al. Consumption-based biodiversity footprints-Do different indicators

$422 \quad$ yield different results? Ecological Indicators 103, 461-470 (2019).

$42373 \quad$ Strassburg, B. B. et al. Global priority areas for ecosystem restoration. Nature 586, 724-

$424729(2020)$.

$42574 \quad$ Tamburini, G. et al. Agricultural diversification promotes multiple ecosystem services

$426 \quad$ without compromising yield. Science advances 6, eaba1715 (2020).

$427 \quad 75 \quad$ Rockström, J. et al. Identifying a safe and just corridor for people and the planet. Earth's

Future, e2020EF001866 (2021). 
Figures

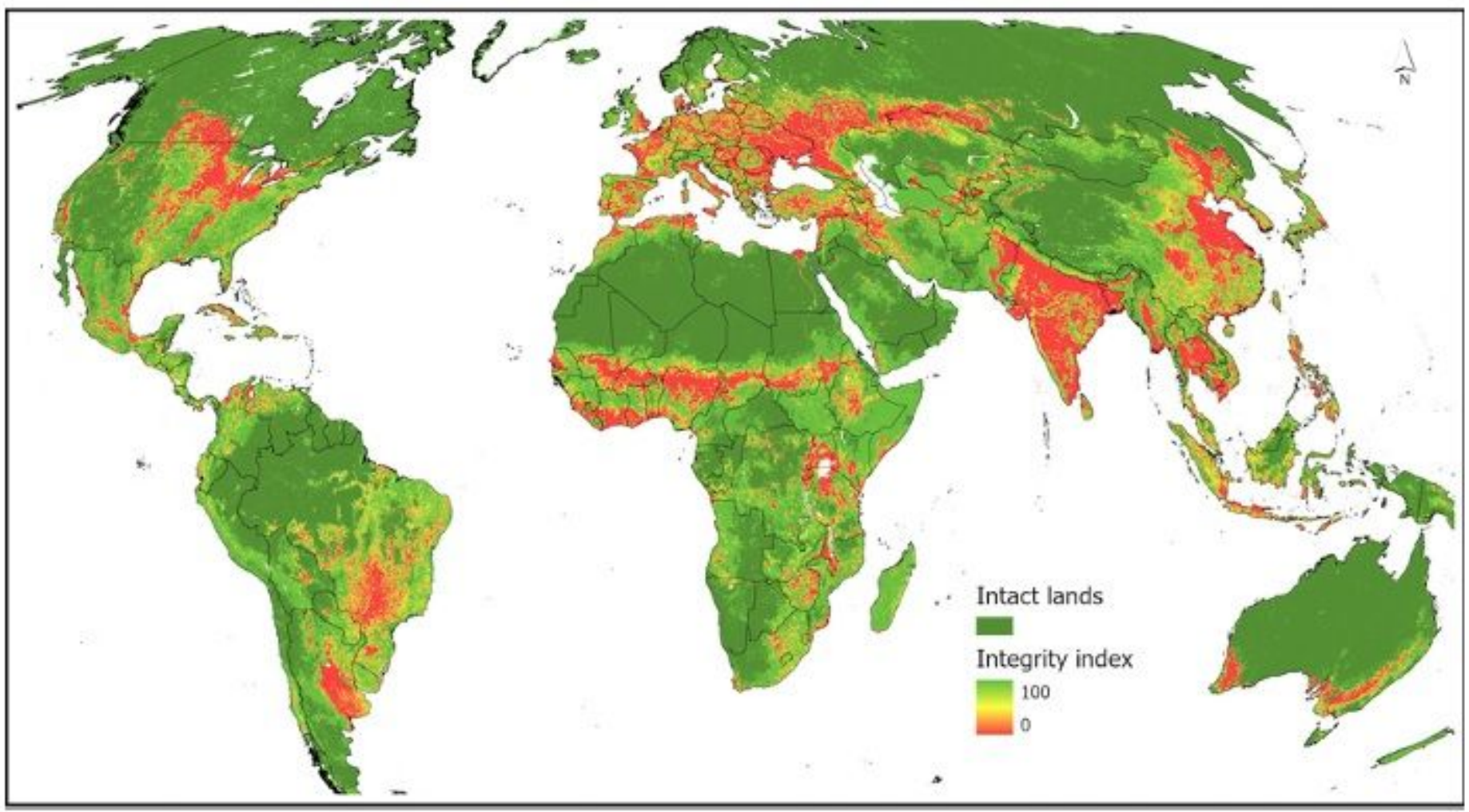

a.
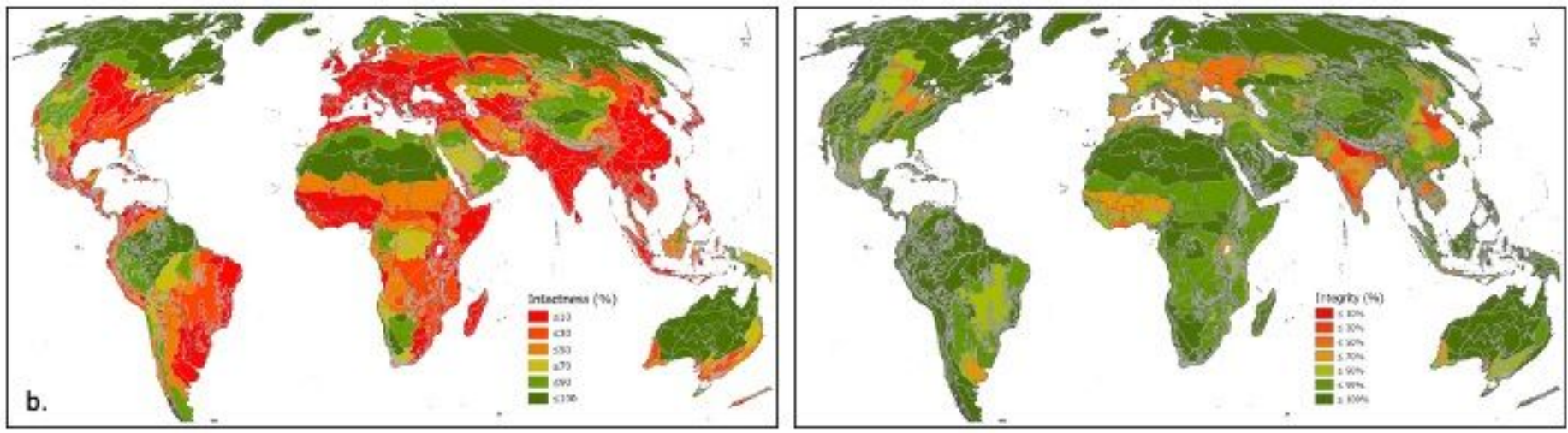

Figure 1

(a) Cell-by-cell measures of intactness (ensemble model Et3) and integrity (10\% embedded natural lands;

(b) Percent intact land by ecoregion; (c) Percent land above the $10 \%$ integrity target by ecoregion. Note:

The designations employed and the presentation of the material on this map do not imply the expression of any opinion whatsoever on the part of Research Square concerning the legal status of any country, territory, city or area or of its authorities, or concerning the delimitation of its frontiers or boundaries. This map has been provided by the authors. 


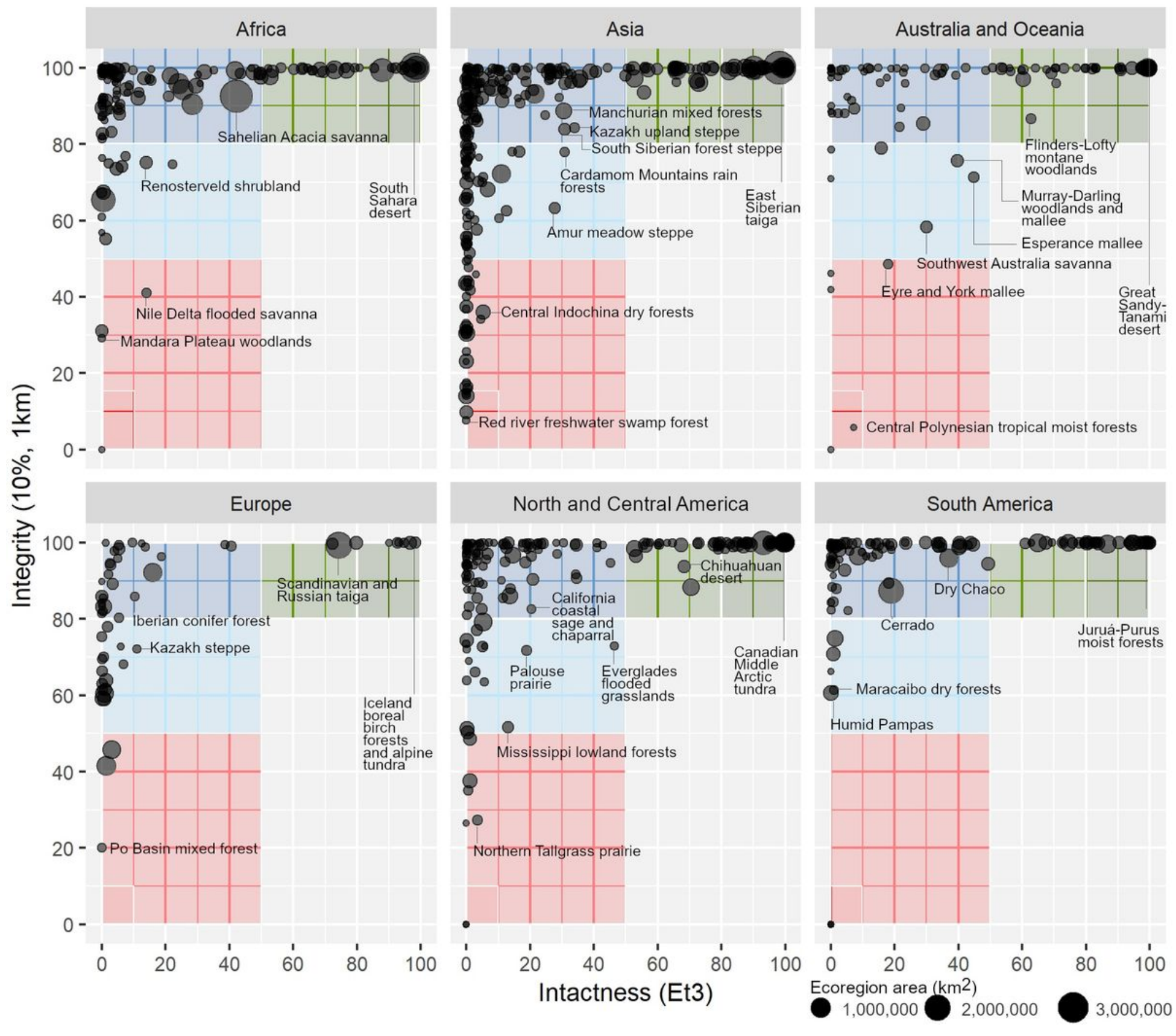

Figure 2

Intactness and Integrity values for each ecoregion plotted by biome; point size is relative to the size of the ecoregion in question. Colored bins show ecoregions with show intersection of regions with low (<40\%), medium (40-60\%), medium-high (60-80\%), and high (>80\%) intactness; and low (<50\%), medium (50-80\%), and high (>80\%) integrity. 


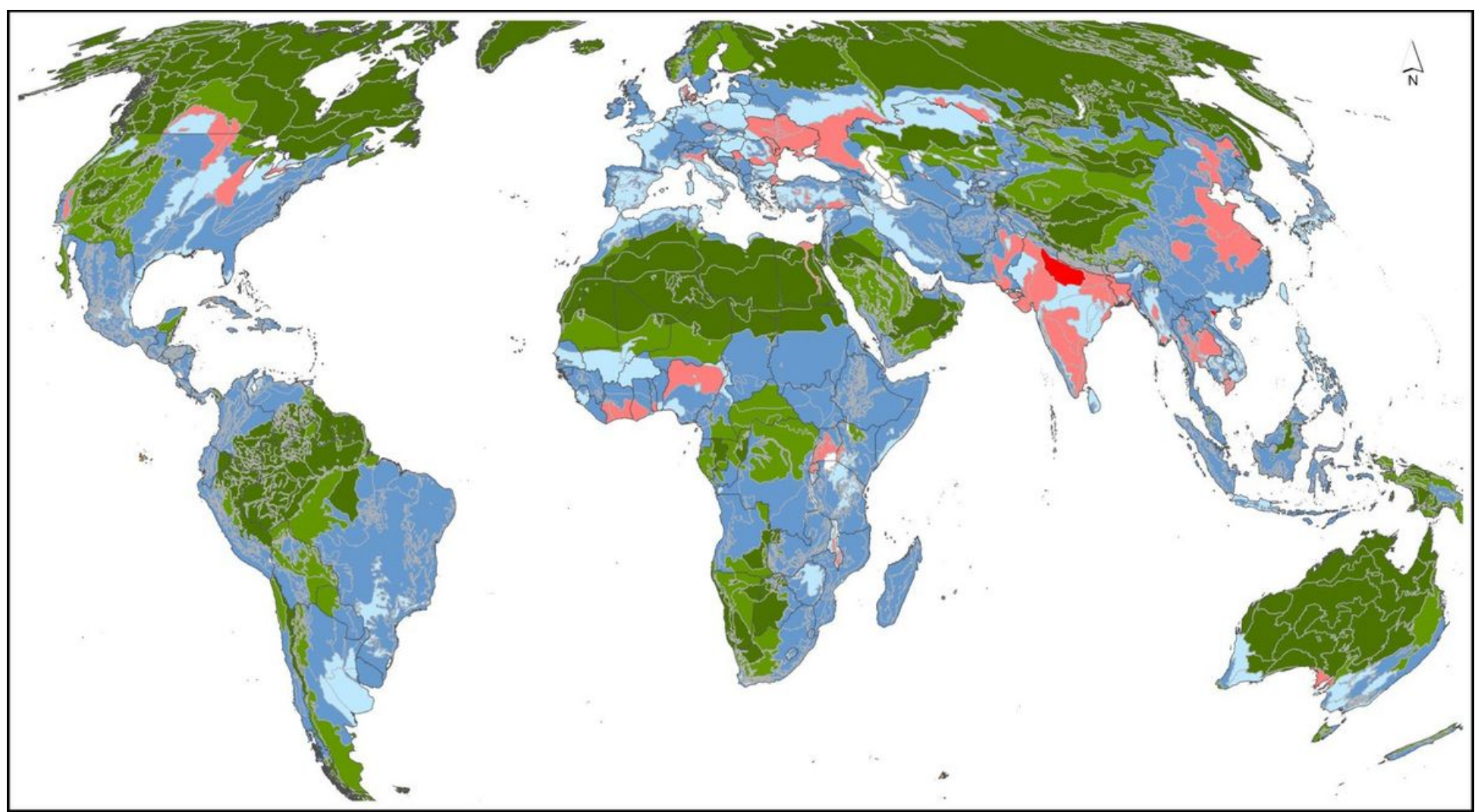

Figure 3

Mapped Intactness and Integrity values for each ecoregion; Colored bins are taken from figure 2. Note: The designations employed and the presentation of the material on this map do not imply the expression of any opinion whatsoever on the part of Research Square concerning the legal status of any country, territory, city or area or of its authorities, or concerning the delimitation of its frontiers or boundaries. This map has been provided by the authors.

\section{Supplementary Files}

This is a list of supplementary files associated with this preprint. Click to download.

- ShareSpareSupplementalTablesXFiguresSubmitted.pdf 